Artigo

\title{
Implementação da Matemática Moderna no ensino secundário português: relatos de uma experiência pedagógica ${ }^{1}$
}

\author{
Implementation of Modern Mathematics in Portuguese secondary education: reports of a \\ pedagogical experience
}

\author{
Implementación de las Matemáticas Modernas en la educación secundaria \\ portuguesa: informes de una experiencia pedagógica
}

Teresa Maria Pires Monteiro ${ }^{2}$
(iD) $[0000-0003-2745-9631]$

\begin{abstract}
Resumo
O início do movimento da Matemática Moderna português coincide com a reabertura dos estágios pedagógicos na Escola Secundária de Pedro Nunes (denominação atual) de Lisboa, em 1956. O metodólogo de Matemática desta Escola, Jaime Furtado Leote, faz parte de uma comissão nomeada ministerialmente, em 1963, para a revisão dos programas de Matemática dos dois últimos anos liceais, atuais $10^{\circ}$ e $11^{\circ}$ anos de escolaridade. Sabendo que a cultura escolar não muda por decreto, o objetivo deste artigo é dar a conhecer relatos dos estagiários desta Escola, sobre a implementação da experiência pedagógica da Matemática Moderna por eles vivida, que mostram uma realidade que não circulou nos canais oficiais e, portanto, menos difundida. Para o feito, procurámos e analisámos fontes primárias, nomeadamente, 30 trabalhos escritos produzidos pelos estagiários, 18 não publicados, e entrevistas a 4 ex-estagiários. Feita uma análise de conteúdo qualitativa das fontes concluímos que, mesmo ladeada de forte empenho pessoal e institucional, a implementação da reforma da Matemática Moderna está envolta em fortes dilemas e dificuldades. O aumento do formalismo na matemática aparece como uma necessidade quase vital e os estagiários alertam para o inconveniente do seu uso precoce no ensino. Ao pretender abarcar-se os novos desafios, quer ao nível dos conteúdos, quer das metodologias revela-se difícil definir um programa praticável. Além disso, concluímos que a Escola foi, na teoria e na prática, um centro de ensaios pedagógicos, frequentada por altas personalidades da sociedade portuguesa, que pretendia formar uma elite para comandar Portugal.
\end{abstract}

Palavras-chave: História da educação Matemática. Reformas curriculares. Ensino secundário. Matemática Moderna. Formação de professores.

\begin{abstract}
The beginning of the Portuguese Modern Mathematics movement coincides with the reopening of the pedagogical internships at the Pedro Nunes Secondary School (current name) in Lisbon, in 1956. The Mathematics methodologist at this School, Jaime Furtado Leote, is part of a ministerially appointed commission, in 1963, for the revision of the Mathematics programs of the upper secondary education. Knowing that school culture does not change by decree, the purpose of this article is to make known reports of the interns at this School, on the implementation of the pedagogical experience of Modern

1 Nota da editoria: este artigo é um extrato da tese da autora, disponível em https://run.unl.pt/handle/10362/55168

2 teresamaria.monteiro@gmail.com, Doutora, Professora-adjunta, Instituto Politécnico de Beja, Beja/Portugal.
\end{abstract}


Mathematics lived by them, which show a reality that was not circulated in official channels and, therefore, less widespread. For this purpose, we searched and analyzed primary sources, namely, 30 written works produced by the interns, 18 unpublished, and interviews with 4 former interns. After a qualitative content analysis of the sources, we concluded that, despite the strong personal and institutional commitment, the implementation of the Modern Mathematics reform is involved in strong dilemmas and difficulties. The increase of formalism in mathematics appears as an almost vital need and trainee teachers warn against the inconvenience of its early use in teaching. When trying to embrace the new challenges, both in terms of content and methodologies, it is difficult to define a practicable program. Furthermore, we conclude that the School was, in theory and in practice, a center for pedagogical essays, who intended to form an elite to command Portugal.

Keywords: History of Mathematics education. Curriculum reforms. High school. Modern Mathematics. Teacher training.

\section{Resumen}

El inicio del movimiento portugués de Matemática Moderna coincide con la reapertura de las prácticas pedagógicas en la Escuela Secundaria Pedro Nunes (nombre actual) en Lisboa, en 1956. El metodólogo de Matemáticas de esta Escuela, Jaime Furtado Leote, forma parte de una comisión nombrada ministerialmente, en 1963, para la revisión de los programas de Matemáticas de los dos últimos años de secundaria, actual décimo y undécimo año de escolaridad. Sabiendo que la cultura escolar no cambia por decreto, el propósito de este artículo es dar a conocer informes de los pasantes de esta Escuela, sobre la implementación de la experiencia pedagógica de la Matemática Moderna vivida por ellos, que muestran una realidad que no circulaba en los canales oficiales $y$, por tanto, menos difundida. Para ello, se buscaron y analizaron fuentes primarias, a saber, 30 trabajos escritos por los pasantes y entrevistas a 4 ex pasantes. Luego de un análisis cualitativa de contenido, concluimos que, a pesar del fuerte compromiso personal e institucional, la implementación de la reforma de la Matemática Moderna está envuelta en fuertes dilemas y dificultades. El aumento del formalismo en las matemáticas aparece como una necesidad casi vital y los pasantes advierten sobre los inconvenientes de su uso temprano en la enseñanza. Al tratar de aceptar los nuevos desafíos, tanto en términos de contenidos como de metodologías, es difícil definir un programa viable. Además, concluimos que la Escuela era, en teoría y en la práctica, un centro de ensayos pedagógicos, que pretendían formar una élite para comandar Portugal.

Palabras claves: Historia de la educación matemática. Reformas curriculares. Enseñanza secundaria. Matemáticas Modernas. Formación de profesores.

\section{Introdução}

Sabendo que a cultura escolar (JULIA, 2001; FRAGO, 2007) não muda por decreto, o objetivo deste artigo é dar a conhecer relatos dos estagiários do Liceu Normal de Pedro Nunes de Lisboa, sobre a implementação da experiência pedagógica da Matemática Moderna por eles vivida, que mostram uma realidade que não circulou nos canais oficiais e, portanto, menos difundida.

Neste estudo, detemo-nos no período temporal de 1956 a 1969 e no Liceu Normal de Pedro Nunes. A escolha do período em análise e deste Liceu prende-se com o início de uma nova fase das políticas educativas portuguesas que, entre outras alterações legislativas e de procedimentos, levam a uma mudança do nome e das funções deste estabelecimento de ensino. 
Em 1956, passa da designação de Liceu Nacional Pedro Nunes para a de Liceu Normal de Pedro Nunes e reabrem os estágios pedagógicos.

Entre 1956 e 1969 refletiu-se no Liceu Normal de Pedro Nunes o movimento internacional da Matemática Moderna, que ocorreu em meados do século XX. Este movimento enquadra-se na era científica, do pós-guerra, uma nova fase da revolução industrial, onde se apela a uma mão-de-obra qualificada, nomeadamente a vários tipos de técnicos, cientistas e professores de alto nível de formação. O metodólogo de Matemática desta Escola, Jaime Furtado Leote, fez parte de uma comissão nomeada ministerialmente para a revisão dos programas de Matemática dos dois últimos anos liceais, que correspondem aos atuais $10^{\circ}$ e 11 을 anos de escolaridade. A comissão foi nomeada pelo ministro Galvão Telles, em julho de 1963, e presidida por José Sebastião e Silva.

Em 1969 é reformulado e legislado o tempo de duração do estágio pedagógico, passando de dois anos letivos para um ano letivo, que coloca em marcha uma nova reforma do sistema educativo português.

Este estudo baseia-se essencialmente em fontes primárias, como sejam livros de sumários de aulas, atas de reuniões, trabalhos dos estagiários, livros escolares de Matemática, artigos publicados, exames e legislação, bem como, em entrevistas a ex-estagiários.

Identificámos trinta e nove estagiários no Liceu Normal de Pedro Nunes no período de 1956 a 1969 e encontrámos trinta trabalhos escritos no âmbito das Conferências Pedagógicas que faziam parte do seu modelo de formação. Relativamente ao ano de 1959, segundo ano de funcionamento destes estágios e correspondendo aos dois anos letivos de 1957/1958 e de 1958/1959, embora seja o ano com o maior número de estagiários, seis no total, só dispomos de um resumo de uma página de um único trabalho publicado na revista Palestra no 5 de 1959. Nos respectivos livros de arquivo do Liceu Normal de Pedro Nunes não consta qualquer trabalho escrito no âmbito da Conferência Pedagógica de 1959. Relativamente ao ano de 1969, embora também tenham existido cinco estagiários, o trabalho escrito no âmbito da Conferência Pedagógica resultou pela primeira vez num trabalho de grupo.

Encontrámos ainda ex-estagiários, com uma idade avançada, e foi possível fazer entrevistas a quatro deles. Um senhor e três senhoras. Muitos anos depois e longe de encontrarmos alguma necessidade de mascarar alguma verdade, os discursos das entrevistas realizadas para este trabalho, entre 2010 e 2015, coincidem com os discursos dos textos. Neste caso também se podia colocar a questão de o tempo apagar e limar o menos bom, mas mais uma vez, pelas razões já apresentadas e por outras que iremos expor, não nos parece que seja esse o caso. As entrevistas com ex-estagiários de Matemática do Liceu Normal de Pedro Nunes realizaram-se nas suas residências, foram gravadas com a devida autorização e foi sempre muito bem recebida a explicação do objetivo do nosso estudo. Todas elas se desenrolaram em conversas muito fluidas, independentemente da idade avançada dos intervenientes, e foram essencialmente livres e exploratórias (BOGDAN e BIKLEN, 1999). Foram realizadas de forma completamente independente, isto é, pessoas diferentes entrevistadas em dias diferentes. Assinalamos a grande clareza de exposição, pormenores precisos de memórias e unanimidade de opiniões relativamente à prática realizada durante 0 estágio pedagógico no Liceu. Os relatos repetem-se, quer pela mesma pessoa em momentos diferentes, quer por pessoas diferentes em diferentes momentos.

Realizámos uma análise de conteúdo qualitativa focada nas alterações que o movimento da Matemática Moderna introduzia, sobretudo na prática letiva. 


\section{Liceu Normal de Pedro Nunes}

As várias denominações da atualmente designada Escola Secundária de Pedro Nunes (Decreto-Lei no 80/78, de 27 de abril de 1978), quase todas determinadas por decreto ministerial, refletem, em cada momento, os objetivos estabelecidos para este estabelecimento de ensino secundário. Muitas vezes, esses objetivos estiveram bastante próximos da formação de professores. Como facilmente se pode observar pelas designações que esta Escola (fundada em 1906) teve ao longo do tempo, a história da formação de professores da disciplina de Matemática neste Liceu também é uma história da prática pedagógica e dos estágios, da educação e das políticas educativas portuguesas, num certo período:

O Liceu Normal de Lisboa fica constituindo um meio de aperfeiçoamento de toda a organização e da melhor execução dos serviços do ensino liceal, visto que será, simultaneamente, escola prática do magistério e aperfeiçoamento profissional, e, sem prejuízo das atribuições da Junta de Educação Nacional, centro de ensaios pedagógicos. (Decreto № 18973, de 28 de outubro de 1930, p. 2209)

Como mostrado no Quadro 1, a primeira designação foi a de Lyceu Central da 3a zona escolar de Lisboa, também conhecido por Lyceu da Lapa (1906-1911), criado, antes da 1a República, pelo Decreto-Lei de 4 de janeiro de 1906, cujo início de funcionamento ocorreu no ano letivo de 1905/1906. O primeiro conselho deste Lyceu teve a presidência do Dr. António Joaquim de Sá Oliveira, um professor com formação jurídica, que foi o seu primeiro reitor de 1906 a 1918. Mais tarde, Sá Oliveira voltou a ser reitor do Liceu, por nomeação do Governo, de 1930 até à data da sua reforma em 1941.

Quadro 1 - Várias designações do Liceu e seus reitores

\begin{tabular}{c|c|c|c}
$\begin{array}{c}\text { Anos } \\
1905-1911\end{array}$ & $\begin{array}{c}\text { Nome } \\
\text { Lyceu Central de } \\
\text { Lisboa, 3. zona } \\
\text { escolar, à Lapa }\end{array}$ & $\begin{array}{c}\text { Local } \\
\text { Largo do Carmo e } \\
\text { Rua do Sacramento } \\
\text { à Lapa }\end{array}$ & $\begin{array}{c}\text { Reitor e sua formação } \\
\text { 1906-18: Sá Oliveira (Direito) }\end{array}$ \\
\hline $\begin{array}{c}\text { 1911-1930 } \\
\text { (com estágios a } \\
\text { partir de 1915) }\end{array}$ & $\begin{array}{c}\text { Lyceu Central de } \\
\text { Pedro Nunes }\end{array}$ & $\begin{array}{c}\text { Avenida Álvares } \\
\text { Cabral }\end{array}$ & $\begin{array}{c}\text { 1906-18: Sá Oliveira (Direito); } \\
\text { 1918-19: Agostinho de Campos (Direito, } \\
\text { embora lecionasse Alemão); } \\
\text { 1919-30: Ramos e Costa (Matemática) }\end{array}$ \\
\hline $\begin{array}{c}\text { 1930-1936 } \\
\text { (com estágios) }\end{array}$ & $\begin{array}{c}\text { Liceu Normal de } \\
\text { Lisboa }\end{array}$ & idem & 1930-41: Sá Oliveira (Direito) \\
\hline $\begin{array}{c}\text { 1936-1956 } \\
\text { (com estágios } \\
\text { até 1947) }\end{array}$ & $\begin{array}{c}\text { Liceu Nacional } \\
\text { Pedro Nunes }\end{array}$ & idem & $\begin{array}{c}\text { 1930-41: Sá Oliveira (Direito) } \\
\text { 1941-56: Xavier Lôbo (Matemática) }\end{array}$ \\
\hline $\begin{array}{c}\text { 1956-1978 } \\
\text { (reabertura dos } \\
\text { estágios em } \\
1956)\end{array}$ & $\begin{array}{c}\text { Liceu Normal de } \\
\text { Pedro Nunes }\end{array}$ & idem & $\begin{array}{c}1956-67: \text { Francisco Dias Agudo (Matemática); } \\
1967-72: \text { Jaime Furtado Leote (Matemática); } \\
1972-74: \text { Silva Mota (Português) }\end{array}$ \\
\hline
\end{tabular}

Fonte: Legislação vária.

De 1930 a 1936, reitor do Liceu Normal de Lisboa, como passou a designar-se o Liceu em consequência do Decreto no 18973 da Secretaria Geral do Ministério da Instrução Pública, de 16 de outubro de 1930, publicado a 28 de outubro do mesmo ano. Como se verá mais 
adiante, este curto Decreto traz alterações profundas ao modelo de formação de professores. Modelo esse que vigorou durante quase quarenta anos. De 1936 a 1941, reitor do agora designado Liceu Nacional Pedro Nunes (ver Quadro 1).

Na segunda fase em que Sá Oliveira é reitor do Liceu, 1930-1941, este assume uma posição muito relevante na própria definição da legislação dos anos 30 do século $\mathrm{XX}$, talvez devido à sua formação jurídica e por tudo no Liceu estar regulamentado. Nomeadamente, sobre a formação de professores e a organização dos liceus normais, como até já estava previsto no Arto 32ㅇ do Decreto no 18973, de 28 de outubro de 1930: "As modificações no regime liceal experimentadas neste Liceu com bons resultados podem ser mandadas adoptar pelo Governo em todos os liceus ou apenas naqueles que para tanto reúnam as condições necessárias" (p. 2211-2212).

Embora apareça a referência ao início dos estágios de professores, na atual Escola Secundária de Pedro Nunes, como sendo no início dos anos trinta do século $\mathrm{XX}$, por determinação do Decreto no 18973 supracitado, na verdade, já existia a componente da prática pedagógica, com a duração de dois anos, desde 1915, no âmbito da formação ministrada pelas Escolas Normais Superiores das Universidades de Coimbra e de Lisboa, criadas em 1911 e que começaram a funcionar em 1915/1916, no então designado Lyceu Central de Pedro Nunes.

Os reitores são portadores de duas formações de base até 1972. A de direito, que totalizou 24 anos na reitoria, e a de matemática, esta maioritária, que totalizou 42 anos na reitoria. No período em estudo, que vai de 1956 a 1969, inicia-se a reitoria de Dias Agudo seguida da reitoria de Furtado Leote, ambos com formação em matemática.

O reitor Francisco Dias Agudo, com formação em matemática, é quem acompanha o Liceu ao longo de quase todo o nosso período de estudo e quem criou a Revista de Pedagogia e Cultura, Palestra, cujo número 1 sai no ano de 1958. Esta revista, uma publicação do Liceu, subsidiada pelo Estado Português e divulgada para os outros liceus do país, terminou com o número 42 em 1973 e teve, entre outros, um papel fundamental na divulgação a nível nacional da experiência pedagógica alvo deste estudo.

Antes, de 1906 a 1939, havia no Liceu uma outra publicação, o Boletim do Liceu Normal de Lisboa (Pedro Nunes), cuja capa continha as palavras: o que se fez, como se fez, porque se fez. Entre 1906 e 1917 existiu ainda o Anuário, que era o relatório anual do reitor e, entre 1906 e 1942, o jornal de nome Os Novos publicado pela Associação Escolar. Esta Associação era constituída por alunos, professores, antigos alunos e outras personalidades propostas pela sua Direção. O lema era: nós nos educaremos. Teve de ser extinta, em 1942, com a chegada da Mocidade Portuguesa ${ }^{3}$.

Alguns dos trabalhos escritos pelos estagiários no âmbito da sua formação foram publicados na revista Palestra.

O Liceu Normal de Pedro Nunes e o seu contexto têm pouco de normal. Sabemos disto, mas disto também já tinha consciência quem por lá passou, nomeadamente os nossos estagiários de Matemática:

primeiro as turmas do Pedro Nunes eram muito boas. Aquilo era uma escola chamada normal, chamava-se liceu normal, mas aquilo não era normal. Era anormal no meio das

3 A Organização Nacional Mocidade Portuguesa, vulgarmente conhecida por Mocidade Portuguesa e criada pelo Decreto-Lei n. 26 611, de 19 de maio de 1936, era uma organização juvenil do regime do Estado Novo português. Os jovens dos sete aos catorze anos estavam obrigados a integrá-la. 
escolas, porque realmente era uma elite de alunos e em todos os campos, e professores também. Tinha lá professores excecionais. O professor Rómulo de Carvalho na Física, havia outros professores muito bons. Eu acho que tive, tivemos, uma aprendizagem muito boa. Foram dois anos muito puxados, mas valeu apena. Deu-nos uma bagagem muito grande. (M. I. SANTOS, entrevista pessoal na sua residência em Lisboa, 14 de novembro de 2014)

Ou, nas palavras de outro estagiário, "era um Liceu de elites. O Liceu Normal de Pedro Nunes era um Liceu de elites. Para dar uma feição não propriamente de elite salpicavam assim com uns mais, de origem mais humilde. Mas normalmente era de elites" (REDINHA, entrevista pessoal na sua residência em Lisboa, 27 de novembro de 2010).

Entre os ex-alunos da Escola Secundária de Pedro Nunes estão, entre outas individualidades, três presidentes da República: Américo Deus Rodrigues Tomás, Jorge Fernando Branco de Sampaio e Marcelo Rebelo de Sousa, dois primeiros-ministros: Alfredo Nobre da Costa e Francisco Pinto Balsemão e um ministro da educação: Nuno Crato.

\section{Modelo de formação}

O modelo de formação de professores para o ensino liceal que vamos analisar permaneceu durante quase quarenta anos, de 1930 a 1969. No período em análise, vive-se em Portugal no regime político do Estado Novo, com a inibição da livre expressão crítica.

De 1956 a 1969, a formação de professores no Liceu Normal de Pedro Nunes tem por base o modelo de formação lançado pelo Decreto no 18973, de 28 de outubro de 1930 , que criou os Liceus Normais de Lisboa e de Coimbra: o Liceu Normal (de Pedro Nunes) de Lisboa e o Liceu Normal (Dr. Júlio Henriques) de Coimbra. Em 1936 os liceus José Falcão e Dr. Júlio Henriques fundem-se, dando origem ao Liceu D. João III, com mudança de instalações, correspondendo hoje à Escola Secundária José Falcão. É um Decreto que ocupa apenas quatro páginas completas e umas poucas linhas do Diário do Governo, I Série, n.o 251, de 16 de outubro e publicado a 28 de outubro de 1930. Está dividido num preâmbulo que ocupa uma página inteira e quarenta e oito artigos que ocupam praticamente três páginas, uma das quais quase toda ocupada por disposições transitórias. É composto por cinco capítulos: I - Da preparação dos professores do ensino liceal e de determinadas disciplinas do ensino técnico profissional; II - Das secções de ciências pedagógicas das Faculdades de Letras; III - Da prática pedagógica dos candidatos ao magistério liceal; IV - Dos liceus normais; V - Disposições transitórias.

Este modelo de formação compõe-se de duas partes: a da cultura pedagógica e a da prática pedagógica e culmina com a realização das provas do Exame de Estado que conferia a habilitação para o magistério. A cultura pedagógica é ministrada nas Universidades com a duração de um ano letivo e a prática pedagógica do ensino liceal efetua-se nos liceus normais na forma de estágio com a duração de dois anos letivos, não remunerados. As cadeiras de cultura pedagógica constituem a 3 a secção das Faculdades de Letras. A aprovação nestas cadeiras era indispensável para a matrícula no $2^{\circ}$ ano de estágio. A habilitação indispensável para a admissão ao 10 ano de estágio, no caso do 8o grupo (grupo de docência do ensino liceal ao qual pertencia a disciplina de Matemática), era a licenciatura na secção de ciências matemáticas das Faculdades de Ciências com a duração de quatro anos. Para ter acesso a mais pormenores sobre este modelo de formação e a sua aplicação, consultar (MONTEIRO, 2018).

Neste estudo analisámos 30 trabalhos escritos pelos estagiários no âmbito das Conferências Pedagógicas que eram 
de duas espécies: a) Reuniões destinadas a promover o convívio entre os professores que no liceu exerçam o ensino e todos os estagiários e a destes entre si, a promover a mais larga cultura dos estagiários, principalmente em relação a todo o ensino realizado no liceu, e a familiarizá-los com os métodos usados em todas as disciplinas liceais; b) Dissertação sôbre assuntos de carácter científico ou pedagógico. (Art.ㅇ 32.ㅇ do Decreto no 24676, 22 de novembro de 1934).

No Liceu Normal de Pedro Nunes no período em estudo, as Conferências Pedagógicas abrangiam as duas componentes: realização de um trabalho escrito individual (dissertação) e realização de uma Conferência (reunião). Todos os estagiários de todos os grupos disciplinares do Liceu redigiam uma dissertação e participavam nas Conferências (Pedagógicas). Para cada ano letivo e relativamente ao $8^{\circ}$ grupo, grupo disciplinar que incluía a Matemática, era definido um tema único, pelo metodólogo, para todos os estagiários do grupo. Também em cada ano letivo, com algumas poucas exceções, era sorteada uma dissertação por grupo disciplinar para ser apresentada na respectiva Conferência (Pedagógica) perante todos os docentes e estagiários do Liceu Normal de Pedro Nunes e até outras personalidades de relevo no domínio da educação nacional presentes na sessão solene. Em geral, as dissertações sorteadas para a Conferência eram posteriormente publicadas na revista Palestra, por vezes numa versão mais curta relativamente ao trabalho original, como tivemos oportunidade de observar.

\section{Quotidiano dos estagiários do Liceu Normal de Pedro Nunes}

Os estagiários assistiam a aulas, quer lecionadas pelo metodólogo, quer pelos colegas de estágio que estavam nos primeiro e segundo anos de estágio, e estas eram seguidas de discussão. Também existiam reuniões semanais/quinzenais entre os estagiários e o metodólogo para discutirem vários assuntos de interesse, nomeadamente temas de Matemática Moderna e aulas observadas.

No primeiro, era um ano em que nós intervínhamos menos nas aulas, mas já começávamos a intervir, mas... Cada um se ocupava de uma ou duas semanas, consoante os assuntos, de dar aquele grupo de lições. No final da aula havia a discussão. Depois, havia sempre, suponho que duas vezes por semana, uma reunião formal para aprofundar essas discussões e esses assuntos relacionados com essas questões práticas. E às vezes não só práticas, também científicas. (REDINHA, entrevista pessoal por telefone, 19 de novembro de 2010)

Maria Inês Santos, estagiária quatro anos depois, menciona encontros quinzenais e acrescenta: "havia sempre um tema e havia sempre uma pessoa que orientava a sessão, que era para aquilo não ser assim muito improvisado. Havia sempre uma pessoa que estudava o tema" (M. I. SANTOS, entrevista pessoal na sua residência em Lisboa, 14 de novembro de 2014). Para além destes encontros, esta ex-estagiária também relata as discussões críticas que ocorriam depois da lecionação de aulas:

Durante estágio, sempre que nós dávamos aulas, após a aula havia crítica com o metodólogo em que participávamos todos os estagiários. E o metodólogo começava por dizer àquele que deu a aula: - Diga lá o que sentiu, o que correu bem e o que correu mal. - Depois falavam os outros colegas de estágio e por fim falava o metodólogo. Eu acho que aprendi muito com isso. Primeiro, nós ao fazermos a nossa autocrítica corrigimos um bocadinho, mas também 
aprendíamos muito com os outros, não é? (M. I. SANTOS, entrevista pessoal na sua residência em Lisboa, 14 de novembro de 2014)

Noutra entrevista, Joaquim Simões Redinha refere mais pormenores: "O Leote e os estagiários davam as aulas todas. As turmas eram de todos. (...) Depois da aula havia uma discussão. Eu lembro que... acho que nunca tínhamos aulas seguidas" (REDINHA, entrevista pessoal na sua residência em Lisboa, 27 de novembro de 2010). Maria Alzira Santos, colega de estágio da Maria Inês Santos, corrobora a prática das turmas serem de todos: "nós não tínhamos propriamente uma turma. Nós tínhamos era unidades, quando o metodólogo achava que era o momento dizia-nos: - Vocês vão dar esta unidade três aulas. - E depois era outra colega" (M. A. SANTOS, entrevista pessoal na sua residência em Lisboa, 8 de junho de 2015). Pelo que, os estagiários não eram responsáveis por uma qualquer turma específica.

Na relação de trabalho de Jaime Furtado Leote com os estagiários, há indícios da crítica ser feita de forma construtiva e nos dois sentidos:

nós saíamos da sala... discutíamos logo provisoriamente... fez aquilo, fez aqueloutro..., mas às vezes também dizíamos em relação a ele. Se calhar não era com o mesmo à vontade. Mas pronto. Mas também Ihe dizíamos em relação a ele: - Oh Sr. Dr., aquele aluno ficou para ali assim e tal... nunca disse nada... o Sr. não tomou conta dele... - Isso dizia-nos a nós também. - Isso não se pode fazer. A turma é a turma. Todos têm de ser solicitados. Se não fazem mais, fazem menos, mas fazem. - Mas isso é que as pessoas não conseguem fazer. Gastei a minha vida toda a tentar que isso [risos] que isso fosse realidade. Eu próprio também não consigo muito. Mas tentava. (REDINHA, entrevista pessoal na sua residência em Lisboa, 27 de novembro de 2010)

Bem como de haver alguma humildade da parte de Jaime Furtado Leote, ao admitir que havia conceitos científicos que podia não dominar à época:

depois a minha colega de estágio, como disse tinha sido assistente da Faculdade do doutor, não sei se ouviu falar, o doutor Almeida Costa. O professor Almeida Costa, que era um homem exigentíssimo. Ele vinha lá do Porto e aquilo era um horror. Nós entrávamos uma centena de alunos e por ano passavam vinte ou vinte e poucos. De maneira que ela, como foi assistente dele, tinha uma bagagem científica que o nosso metodólogo até dizia: - Quando eu tiver dúvidas científicas recorro aqui à Alzira. (M. I. SANTOS, entrevista pessoal na sua residência em Lisboa, 14 de novembro de 2014)

Da opinião que apurámos entre os estagiários, há unanimidade do quanto foi proveitoso para todos aquilo que aprenderam na sua prática de dois anos de estágio. Mesmo entre os estagiários que já tinham alguns anos de experiência de lecionação antes de ingressarem no estágio de Matemática do Liceu Normal de Pedro Nunes. E destacam que o mesmo não acontecia noutros locais onde também existiram estes estágios.

\section{Visão dos estagiários sobre a implementação em curso da Matemática Moderna}

Nesta secção expomos resultados da análise de conteúdo qualitativa efetuada sobretudo aos trabalhos dos estagiários para as Conferências Pedagógicas do Liceu Normal de Pedro Nunes. Esta análise focou-se essencialmente no que pode retirar-se sobre a visão dos estagiários relativamente à experiência pedagógica, iniciada oficialmente em 1963, da 
implementação da Matemática Moderna no ensino secundário português. No âmbito desta reforma do ensino da Matemática foram criadas turmas piloto, também designadas por turmas experimentais. Os textos para estas Conferências, sendo trabalhos individuais (com a exceção do último que foi de grupo), são vestígios do que os estagiários viram, ouviram e refletiram a partir das aulas e das discussões que tiveram, da bibliografia a que acederam e das suas vivências do dia a dia.

A estagiária Maria Alzira Santos faz referência às primeiras três turmas experimentais portuguesas, exatamente do 60 ano liceal (atual 10 을 ano de escolaridade), uma em cada um dos liceus normais, o de Lisboa, o de Coimbra e o do Porto, o último decretado em setembro de 1957. Refere também a evolução do nível, número e local destas turmas, de 1963/1964 até 1966/1967. Ao longo destes quatro anos, a experiência ganhou amplitude com a criação de mais turmas, primeiro noutros liceus de Lisboa, Porto e Coimbra, mais tarde em liceus de outras cidades do país. No ano de 1966/1967 funcionaram 25 turmas de 6o ano e 19 turmas de 7ㅇ ano. $O$ alargamento, para além das três cidades principais, deu-se apenas no ano de 1966/1967. Assim, nas cidades de Faro, Braga, Castelo-Branco, Portalegre e Évora, só em 1966/1967 se iniciou a experiência onde funcionaram cinco turmas de 60 ano, uma por cidade. Cada turma experimental compôs-se de vinte e cinco alunos. Para as primeiras turmas experimentais os alunos foram selecionados, mas tal não aconteceu sempre para todas as turmas. Uma das turmas experimentais do 60 ano, do Liceu Pedro Nunes, em 1966/1967, tinha vários alunos que nos três períodos de 6으 ano somaram 29 valores em Matemática e mesmo outros reprovados. A inscrição nas turmas experimentais era precedida de uma consulta aos encarregados de educação e recebida com grande entusiasmo, quer por estes, quer pelos alunos. "Mesmo os alunos mais fracos fazem empenho em frequentar as classes-piloto" (M. A. SANTOS, 1967, p. 7). Relativamente aos professores, estes recebiam uma remuneração extra:

Os professores a quem são confiadas as turmas experimentais, recebem uma remuneração especial do Gabinete de Estudos e Planeamento da Acção Educativa, organismo que superintende todas as actividades ligadas à experiência, incluindo a parte económica. Sobre estas despesas o Ministério da Educação Nacional tem recebido da O. C. D. E. um contributo de $40 \%$. Este ano a comparticipação da O. C. D. E., não se verificou, mas espera-se que (...) o esquema dos anos anteriores se mantenha. (M. A. SANTOS, 1967, p. 7)

As renovações que se impuseram na introdução da Matemática Moderna no ensino liceal foram essencialmente de três ordens: novos conteúdos que foram introduzidos nos programas, novos métodos pedagógicos e interligação e unificação dos assuntos em estudo. Maria Alzira Santos deixa claro que "a mudança de matérias não arrastava necessàriamente uma renovação de processos didácticos" (1967, p. 14) e justifica com “muitas matérias que se estudam nas classes experimentais, têm sido ensinadas na Universidade por métodos expositivos e por vezes com uma motivação pobre" (1967, p. 14-15). De qualquer forma, esta estagiária e ex-assistente da Faculdade de Ciências da Universidade de Lisboa assume que houve diferenças nos métodos de ensino:

Frisemos desde já que a diferença entre os dois programas [experimental e o que estava anteriormente em vigor] não se limita a alterar o elenco dos assuntos tratados em cada um deles, suprimindo uns capítulos e acrescentando outros, mas consiste numa verdadeira remodelação que 
abrange os dois aspectos.: a) renovação de programas; b) renovação de modos e métodos de ensino. (M. A. SANTOS, 1967, p. 8-9)

Sobre esta mudança de atitudes no ensino da Matemática, Maria Inês Santos aborda a preocupação com a interligação e unificação dos assuntos estudados com um exemplo concreto:

Depois de feita a generalização da noção de ângulo foi necessário definir novas funções circulares, que mantiveram as mesmas designações, para facilitar e por se tratar de extensões das funções anteriormente definidas a partir do triângulo rectângulo. Esta observação permitiu recordar as noções de restrição e de extensão de uma função (...) O enquadramento das funções circulares no quadro da análise matemática foi conseguido através dos números complexos. (M. I. SANTOS, 1967, p. 18)

e acrescenta que os conteúdos "que não são novos são apresentados de uma maneira muito diferente" (1967, p. 28-29).

Sobre considerações gerais de ordem didática para os vários anos e ligando as estruturas psicológicas dos alunos com as algébricas de matemática, o estagiário António Esteves Gomes refere que "o professor de Matemática deverá orientar o aprendizado das propriedades das operações e de ideias matemáticas afins, por forma que se vão descobrindo, aos poucos, as estruturas algébricas dos conjuntos, através das estruturas lógicas do pensamento" (GOMES, 1962, p. 72-73) e apresenta exemplos concretos a ter em conta ao longo dos vários anos liceais:

No[s] 1ํ e 2ㅇ Anos, o professor apresentará: a noção de conjunto, suas operações com exemplos simples relacionados com o estudo e com a vida real; a noção de correspondência, servindo-se das operações aritméticas e falará sobre o "elemento neutro" das operações que o possuem ainda que o não chame pelo seu nome, (na adição e multiplicação), e tratará de operações inversas.

No 3o Ano, poderá referir: 1) o conjunto ser fechado relativamente à adição ou multiplicação; 2) ser comutativo; 3) ser associativo; 4) existência do elemento unidade, do elemento neutro (já nomeado) e do elemento inverso: simétrico aditivo ou inverso multiplicativo. $O$ aluno vai absorvendo, sempre que $o$ assunto permita, a estrutura de grupo.

No 4ㅇ Ano, poderá evidenciar as propriedades de anel com exemplos próprios e adequados ao estudo da lição.

No 50 Ano, seguirá caminho idêntico no que respeita à noção de corpo.

Nos 6ㅇ e 70 Anos, far-se-ia a sistematização das estruturas ensaiadas, apoiada em simbologia lógica, precisa e expressiva. (GOMES, 1962, p. 73, sublinhados no original)

É evidente a preocupação com os conjuntos e as estruturas algébricas que se podem obter quando munimos os conjuntos com uma lei de composição interna. Também é evidente que o aumento da complexidade das estruturas algébricas segue o aumento do ano de escolaridade. Nota-se ainda a preocupação de ir buscar-se exemplos à vida real nos primeiros anos e nos últimos anos a preocupação com a utilização da "simbologia lógica", como 
designavam, bem como a aplicação da adjetivação de precisa e de expressiva a esta simbologia lógica. Em 1962, o estagiário António Esteves Gomes acreditava verdadeiramente, quer no interesse do estudo da teoria dos conjuntos e das estruturas algébricas, quer no proveito que a lógica vinha trazer ao ensino da Matemática. São muitas as facetas que se atribuíram à lógica (MATOS \& MONTEIRO, 2020). No entanto, uma outra estagiária, em 1967, vai buscar um exemplo de 1953 para alertar contra a predominância que se dava ao raciocínio lógico em desfavor de outros dois aspetos considerados também essenciais para o ensino da Matemática. Diz ela, usando o pensamento de Adam Puig, que há "no estudo matemático dos fenómenos naturais três fases: a 1a de planeamento ou abstração, a $2^{a}$ de desenvolvimento do raciocínio lógico e a 3a de tradução do abstracto em concreto, operação a que chamou de concretização" (M. A. SANTOS, 1967, p. 11), mas que o ensino da Matemática se terá reduzido "durante muito tempo quase exclusivamente à segunda fase" (M. A. SANTOS, 1967, p. 12) em detrimento das outras.

A estagiária Maria Alzira Santos continua a sua exposição dizendo que compete à matemática abordar a sério o raciocínio dedutivo, mas que para isso há idades certas a ser respeitadas, caso contrário, "faria morrer o tal gosto pelo raciocínio dedutivo, em vez de o desenvolver, como é nosso desejo." (1967, p. 47).

O interesse da intuição, quer ligada ao estudo inicial da geometria, quer da álgebra, é salientado desde o início destes estágios, assim como são feitos alertas para o inconveniente do uso precoce do formalismo: "Não só o início do estudo da geometria tem necessidade de estar ligado ao intuitivo, mas também o da álgebra. Um prematuro formalismo tornaria não só desagradável este estudo, como comprometeria toda a acção formativa (...) do aluno" (RODRIGUES, 1961, p. 14-15) e Maria Odete Rodrigues remata: "Deixemo-lo [ao aluno] apossar-se primeiro dos conteúdos das situações, sobre eles discorrer e a regra aparecerá por fim, naturalmente, como síntese do próprio conhecimento" (1961, p. 15).

Não são só referências positivas ao trabalho desenvolvido nestes estágios que encontramos nos textos para as Conferências Pedagógicas. A que apresentamos de seguida parece deixar transparecer algum descontentamento e impotência por parte de quem está a começar a lidar com as alterações aos programas trazidas pela introdução da Matemática Moderna. Referimo-nos a: "Como há um programa a cumprir, limitamo-nos a aproveitar todas as oportunidades para alargar os conhecimentos obrigatórios e para os introduzir num campo mais geral onde os situou a álgebra moderna." (MARTINS, 1962, p. 66). A próxima reflexão não deixa de ser um facto e uma constatação da experiência portuguesa ter começado com turmas formadas especialmente pelos melhores alunos:

A comissão decidiu formular um programa geral adaptado aos alunos mais dotados, e apresentou, para cada ciclo [liceal], as suas sugestões, acompanhando estas com a exposição dos objectivos a alcançar, do espírito do ensino e, ainda, da bagagem matemática necessária para abordar esses programas.

Foram essas sugestões que orientaram a experiência portuguesa nos três liceus normais, em 1963-1964. (RUA, 1966, p. 13)

Marília de Jesus Rua continua nos seguintes termos: 
Creio não estar muito longe da verdade se disser (e não sei se esta exposição conseguiu transmitir esta ideia) que, ao longo do ano, os assuntos são "abandonados à pressa" quando "ameaçam transbordar" muito além do que a reconhecida premência doutros assuntos permite.

(...) Não chegou, já, o tempo para o estudo de alguns teoremas da Álgebra de Boole, nem para alguns elementos da Teoria das Probabilidades e Estatística, que só veio a ser feito no 70 ano. (RUA, 1966, p. 25)

Este trabalho no âmbito das Conferências Pedagógicas não foi publicado na revista Palestra. Foi publicada a Conferência Pedagógica do colega Plínio Casimiro Serrote.

Noutros trabalhos para as Conferências Pedagógicas encontramos mais referências ao movimento da Matemática Moderna estar direcionado para elites. Maria Alzira Santos refere que o interesse da OCDE ${ }^{4}$ "pelos problemas do ensino, em particular da matemática" (1967, p. 2) tinha os seguintes objetivos e cita:

"a la nécessité urgent d'accroître le personnel technique; définir le rapport qui existe entre les investissements dans l'enseignement et l'expansion économique (...); enfin fournir une assistance spéciale aux pays qui élaborent leur système[s] d'enseignement de base et posent ainsi les fondements d'un enseignement scientifique et technique de degré supérieur". (M. A. SANTOS, 1967 , p. 3, sublinhado no original)

Era recomendado pela OCDE e havia consciência por parte de quem aplicava estas medidas que se estava a trabalhar para formar quadros superiores. Pretendia-se formar uma certa elite. Este ensino não tinha a pretensão de ser para todos.

A estas dificuldades acresce que os professores começaram a lecionar na experiência pedagógica com falta de livros específicos de apoio às aulas: "A falta foi preenchida, no passado ano lectivo, com a publicação de um 'Compêndio', da autoria do sr. professor doutor Sebastião e Silva (o nome do autor sugere, por si, os méritos da obra)" (RUA, 1966, p. 13). Marília de Jesus Rua acrescenta:

As conclusões da experiência do ano passado (que se efectuou já em 11 turmas) foram, pelo mesmo autor, publicadas num 'Guia Para a Utilização do Compêndio', ao qual, há poucos dias, foram anexos numerosos exercícios de autoria dos professores que regeram turmas.

A experiência do presente ano lectivo, (que se estendeu, agora, a 30 turmas), beneficiou, assim, dos ensinamentos colhidos na anterior. (RUA, 1966, p. 1314)

Noutra perspectiva, o colega Plínio Casimiro Serrote destaca a distribuição gratuita aos alunos do Compêndio de Matemática de Sebastião e Silva e a preço acessível a todos os professores dos liceus:

- E dessa colaboração com a OCDE, que frutos colhemos já?

- Além dos contactos sempre muito úteis com especialistas de outras nações, facultando-nos o conhecimento dos resultados das suas múltiplas

${ }^{4}$ OCDE é a sigla para Organização para a Cooperação e Desenvolvimento Económico. Organização económica intergovernamental fundada em 1961 para estimular o progresso económico e o comércio mundial. 
experiências, tivemos a realização de alguns cursos de aperfeiçoamento para professores que permitiram a criação no 3o ciclo de turmas experimentais ou turmas-piloto, funcionando já em diversos liceus do País. Os alunos destas turmas dispõem de um Compêndio de Matemática e de um Guia para seu uso - distribuídos gratuitamente - da autoria do llustre Prof. Sebastião e Silva, editados pelo Ministério da Educação Nacional nos termos de um acordo com a OCDE.

Estas obras têm sido fornecidas a preço acessível a todos os professores dos liceus e colégios, numa tentativa de acelerar a actualização do maior número possível de agentes do ensino da Matemática. (SERROTE, 1966, p. 110)

Esta situação manteve-se no ano seguinte: "Os livros de texto [de Sebastião e Silva] são distribuídos gratuitamente a todos os alunos e professores das turmas experimentais" (M. A. SANTOS, 1967, p. 7).

Os elementos de estudo para os professores eram escassos e não só em termos de conteúdos, também em formação de didática específica, sobretudo no início destes estágios, onde os próprios professores chegam a desejar cursos de formação no período das férias:

Torna-se urgente a publicação de livros, artigos com orientação científica e pedagógica, encontros, conferências, participação em congressos internacionais (ou nacionais a organizar talvez em férias grandes) para que o professor liceal tome contacto com estas ideias mais profundas. (MARTINS, 1962, p. 71).

No ano seguinte, Sebastião e Silva e Jaime Furtado Leote integram a Comissão de Revisão do Programa do 3ㅇ Ciclo Liceal nomeada por Galvão Telles, em julho de 1963, e decorrem lições do "Curso de Actualização para professores de Matemática dos Liceus" realizadas na Faculdade de Ciências de Lisboa. Por exemplo, a 12a lição foi no dia 20 de março de 1963 e versou sobre: "Grandezas em Matemática e em Física. Produtos tensoriais de grandezas. Espaços vectoriais". O curso foi promovido pelo Centro de Estudos Matemáticos de Lisboa e as lições eram às 18 horas, orientadas por Sebastião e Silva e com uma periodicidade semanal (Diário de Lisboa, 19 e 26 de março de 1963).

Houve outros cursos "de Aperfeiçoamento para Professores" no Liceu de Oeiras, de duas semanas de setembro, período de férias de Verão, repetidos pelo menos de 1964 a 1971 (ALMEIDA, 2013, p. 54, 226, 228). O primeiro foi regido por Sebastião e Silva, destinado a metodólogos e outros professores que no ano seguinte iriam lecionar as turmas experimentais. Antes, em 1959, Sebastião e Silva ministrou um curso de "Introdução à Lógica Simbólica e aos Fundamentos da Matemática" no Liceu Normal de Pedro Nunes.

Nem todos os professores do ensino liceal de Matemática tiveram acesso a estas formações, por razões várias, e mais uma vez é assumido algum elitismo: "comprometendo a maior parte dos professores, ou pelo menos os melhores, se atingirá, de facto, a mentalidade do estudante português - a grande finalidade do nosso ensino liceal" (MARTINS, 1962, p. 71). Os cursos de aperfeiçoamento estavam localizados, essencialmente em Lisboa. Em 1967, Maria Alzira Santos escreve na sua Conferência Pedagógica que o curso de atualização de professores de Matemática de 1964 durou 15 dias e visou o programa escolhido para as turmas experimentais de 60 ano. A inscrição foi feita por convites e o número de participantes foi reduzido. Aos professores que realizaram esse curso foram depois entregues turmas experimentais. 
Uma das exceções foi o trabalho realizado no Liceu Nacional de Évora, onde foram realizados dez colóquios para o Aperfeiçoamento do Ensino da Matemática no Distrito de Évora. Os colóquios realizaram-se entre os meses de novembro e maio do ano letivo de 1965/1966, sob a orientação de Alberto Miranda, professor de Matemática e Vice-Reitor do Liceu Nacional de Évora. Os dois primeiros colóquios, o primeiro a 17 de novembro de 1965 e o segundo a 2 de dezembro de 1965, foram da autoria do próprio Alberto Miranda e intitularam-se, respectivamente, por Sentido de Modernidade - $O$ conjunto $N$ dos inteiros aritméticos e por Consequências imediatas dos axiomas de Peano para uma Relação de Ordem no Conjunto dos Inteiros Aritméticos. Os terceiro e quarto colóquios foram da autoria de duas professoras de Matemática do Liceu de Évora, as professoras Zilda de Oliveira e Júlia Ferreira, com os títulos, respectivamente, Operações sobre Conjuntos, a 12 de Janeiro de 1966, e Conceito de Aplicação, a 26 de Janeiro de 1966; o quinto colóquio foi da autoria de uma professora de Matemática do Colégio de Estremoz, Glória Simião, intitulado Produtos Cartesianos - Relações, a 9 de fevereiro de 1966; o sexto colóquio foi da autoria da Irmã Maria Elisa Castro Lopes, professora de Matemática no Colégio da Nossa Senhora do Carmo, em Évora, a 2 de março de 1966, com o título Leis de Composição; o sétimo colóquio, a 16 de março de 1966, foi da autoria do professor de Matemática do Liceu de Évora, Vicente Saianda, que veio a ser estagiário do Liceu Normal de Pedro Nunes cinco anos letivos depois, com o título Conjuntos Finitos, Conceito de Cardinalidade; o oitavo colóquio foi da autoria do Major André Infante, professor de Matemática no Ensino Particular, Individual, em Évora, a 20 de abril de 1966, com o título Estruturas; o penúltimo colóquio voltou a ser da autoria do professor de Matemática do Liceu Nacional de Évora, Alberto Miranda, a 4 de maio de 1966, com o título Aspectos Didácticos e Pedagógicos e o décimo e último colóquio foi da autoria da professora de Filosofia, Maria Beatriz Serpa Branco, do Liceu de Évora, a 18 de maio de 1966, com o título Aspectos Filosóficos do Colóquio. Da descrição feita e da bibliografia que foi disponibilizada, podemos observar que os temas foram sobretudo de aspetos formais da Matemática Moderna e de Lógica, com a exceção dos dois últimos colóquios, um de didática e pedagogia do ensino da Matemática e o outro de filosofia, e que os seus autores eram sobretudo professores de Matemática do Liceu Nacional de Évora, com a exceção de uma professora de Filosofia e de professores de Matemática de outras instituições de ensino da proximidade, quer oficial, quer particular, num total de três oradores e cinco oradoras.

A maior assistência destes colóquios ocorreu nas primeira e última sessões, com 41 e 37 participantes, respectivamente. As sessões do Vice-Reitor tiveram 41, 29 e 34 participantes, respectivamente, e há referência a que nos dois primeiros colóquios os participantes eram professores do ensino Superior e Secundário do distrito de Évora. Os 24 participantes foram registados no colóquio do senhor Major, tendo os restantes entre 26 e 29 participantes, não incluindo apenas professores de Matemática. Estiveram presentes professores "de Filosofia e de Física a que se agregaram professores de Geografia, de Desenho, de Pedagogia e de Didáctica" (MIRANDA, 1966, sem p.). As súmulas efetuadas eram de uma a três páginas $A 4$ por colóquio, num documento sem numeração de páginas, num total de 31 páginas, incluindo a capa. Como exemplo concreto e relativamente ao primeiro colóquio, a sua finalidade foi:

Familiarizar os professores de Matemática com os métodos modernos de ensino, auxiliando-se mutuamente. Colaborar com os outros núcleos similares a quem se comunicará regularmente as súmulas dos assuntos 
tratados (...) julgados de interesse para o aperfeiçoamento do ensino da disciplina. (MIRANDA, 1966, sem p.)

A intenção pedagógica adotada no colóquio e expressa no mesmo documento foi a de um nível secundário elevado e teve o seguinte programa provisório:

I Construção do Conjunto dos Inteiros Relativos.

II Outros exemplos de conjuntos com o fim de caracterizar estruturas.

III Operações sobre conjuntos.

IV Um problema especial sobre conjuntos (ex: continuidade).

$\checkmark$ Um ou dois problemas de aritmética aplicada (ex: análise combinatória ou estatística). (MIRANDA, 1966, sem p.)

No mesmo documento ainda pode ler-se que, neste mesmo colóquio, Alberto Miranda se referiu:

aos aspectos da Ciência na época actual relacionando-os com o movimento de modernidade em literatura, música, pintura, mostrando uma tendência geral para a espiritualidade, generalização e luta contra preconceitos: poesia subjectiva, conceito de realidade (passado, imaginação humana), música concreta, pintura abstracta, em geral no predomínio da essência sobre a realidade palpável. O preconceito de vazio e o preconceito de espaço tridimensional. O "Conjunto" como ente matemático universal; a Lógica matemática como técnica universal de raciocínio. (MIRANDA, 1966, sem p.)

E, entre outras considerações, foram definidos os cinco axiomas de Peano. O insucesso em Matemática, que continua a ser um problema atual, também foi abordado no colóquio.

Segundo Maria Inês Santos, muitas dificuldades foram ultrapassadas "em condições dignas de registo à custa de uma obstinada boa vontade por parte dos professores, ao seu maior poder de assimilação em face de novas matérias e, sobretudo, à troca de impressões entre eles havida, numa valiosa acção colaborativa" (1967, p. 13), e sublinha que o objetivo era um bem maior que a todos motivava.

Para a estagiária Maria Dulce Nogueira, os objetivos que se pretendiam alcançar para o ensino da Matemática eram, por esta ordem: (1) usar a intuição dos alunos e prepará-los gradualmente para a abstração; (2) exigir rigor nas definições e no desenvolvimento das demonstrações; (3) dar a conhecer aos alunos o método axiomático por meio de uma organização dedutiva dos temas a estudar, nomeadamente os da Geometria e da Aritmética; (4) introduzir o espírito da álgebra moderna de forma prudente; (5) introduzir a lógica simbólica e (5) desenvolver o espírito crítico dos alunos (NOGUEIRA, 1961, p. 39).

Se todas estas alterações exigiram muito trabalho aos docentes, também foram exigentes para os alunos:

Ao pensarmos no programa do terceiro ciclo não podemos deixar de observar que exige esforço da parte dos alunos pois a maioria dos assuntos que faziam parte do programa clássico continuam a ser estudados, embora revestidos dum novo aspecto. Há outros mesmo que foram introduzidos e que não figuravam no anterior. (LEITÃO, 1966, p. 18)

De qualquer forma, apontam-se vantagens para os alunos, "visto que a par de métodos mais atraentes (...) Ihes dá maior abertura de conhecimentos, maior elasticidade de raciocínio 
e os prepara melhor para a vida" (M. I. SANTOS, 1967, p. 29). Duas razões apresentadas para justificar a atração são a exigência de maior participação do aluno e o ensino por parte do professor ser precedido das devidas motivações. Ao mesmo tempo que se registam dificuldades, algumas delas inesperadas: "Apesar de a matéria tratada em trigonometria ser bastante fácil, os alunos não reagiram tão bem como seria de esperar. Talvez tenha contribuído para isso a dispersão dos elementos de estudo à sua disposição" (M. I. SANTOS, 1967, p. 18). Os alunos tinham como elementos de estudo o livro único da autoria de Gonçalves José Jorge Gonçalves Calado, Compêndio de Trigonometria, o Compêndio de Matemática de Sebastião e Silva, o Guia para a utilização do Compêndio de Matemática para o 70 ano do mesmo autor e os apontamentos que tiravam nas aulas.

\section{Considerações finais}

Da análise feita dos trabalhos para as Conferências Pedagógicas destes estagiários, o aumento do formalismo na matemática aparece como uma necessidade quase vital. A palavra "rigor" e a expressão "rigor lógico" são muito utilizadas pelos estagiários. Mas desde o início há consciência das dificuldades da introdução do aumento do formalismo no ensino liceal. De qualquer forma, envereda-se nesta direção, primeiro com alguma incredulidade e paulatinamente (LIMA, 1958; Nogueira, 1961; Vieira, 1960), depois com algum encantamento e menos reservas (MARTINS, 1962; PAIS, 1963; REDINHA, 1963; RIBEIRO, 1966) e, por fim, com o registo de resultados que mostram algumas espinhas do percurso (LEITÃO, 1966, M. A. SANTOS, 1967; M. I. SANTOS, 1967). São feitos alertas para o inconveniente do uso precoce do formalismo e que o ensino da Matemática se terá reduzido durante muito tempo quase exclusivamente ao desenvolvimento do raciocínio lógico. Estava a viver-se um conflito entre o que alguns autores defendiam publicamente como desejável para o ensino da disciplina escolar de Matemática, nomeadamente sobre a introdução de que consideravam um maior rigor por via do uso da lógica e axiomáticas, e a prática destas intenções na sala de aula relativamente às reais capacidades dos alunos.

Outra conclusão que pode retirar-se desta análise é que há um aumento significativo do currículo da Matemática, uma vez que há novos conteúdos introduzidos ao mesmo tempo que se mantêm muitos outros com novas abordagens. O que leva a não se conseguir cumprir o programa, mesmo quando alguns assuntos são deixados à pressa para se passar a outros. Elementos da Teoria das Probabilidades e Estatística era um dos conteúdos que ficavam por leccionar.

Estas dificuldades são expostas mesmo vivendo-se num contexto político de ditadura, numa Escola de excelência, com professores excecionalmente motivados e com alunos especialmente escolhidos. Da opinião que apurámos entre os estagiários, há unanimidade do quanto foi proveitoso para todos aquilo que aprenderam na sua prática de dois anos de estágio. Mesmo entre os estagiários que já tinham alguns anos de experiência de lecionação antes de ingressarem no estágio de Matemática do Liceu Normal de Pedro Nunes. E destacam que o mesmo não acontecia noutros locais onde também existiram estes estágios.

O Liceu Normal de Pedro Nunes foi, na teoria e na prática, um centro de ensaios pedagógicos, frequentada por altas personalidades da sociedade portuguesa, que pretendia formar uma elite. Era assumido pela OCDE, por Sebastião e Silva e pelo metodólogo de Matemática do Liceu Normal de Pedro Nunes que não se pretendia experimentar um ensino para todos, mas um ensino científico e técnico de grau superior para formar técnicos de alto nível. 


\section{Referências}

ALMEIDA, Mária. Um olhar sobre o ensino da Matemática guiado por António Augusto Lopes. Tese de doutoramento, Universidade Nova de Lisboa, Portugal, 2013.

Decreto no 18973. Diário do Governo, I Série (251, 28 de outubro de 1930), p. 2208-2213, 1930.

Decreto no 24676. Diário do Governo, I Série (275, 22 de novembro de 1934), p. 604-616, 1934.

Decreto-Lei de 4 de janeiro de 1906. Legislação Régia, 1906.

Decreto-Lei no 80/78. Diário da República, I Série (97, 27 de abril de 1978), p. 776, 1978.

Diário de Lisboa. Curso de Actualização para professores de Matemática dos Liceus, p. 12. Jornal de 19 de março de 1963.

Diário de Lisboa. Curso para professores de Matemática, p. 9. Jornal de 26 de março de 1963.

FRAGO, Antonio. Sistemas educativos, culturas escolares e reformas. Mangualde: Edições Pedago, Lda., 2007.

GOMES, António. Linha de Rumo do Aprendizado da Matemática Elementar: o Trabalho de Equipa, o Modelo, os Princípios de Lógica Matemática e de Álgebra dos Conjuntos. Retirado do arquivo da Escola Secundária de Pedro Nunes (Não catalogado), 1962.

JULIA, Dominique. A Cultura Escolar como Objecto Histórico. Revista Brasileira de História da Educação, n.1, p. 9-43, 2001.

LEITÃO, Marinete. Algumas considerações sobre o 60 ano de Matemática das turmas experimentais: conteúdos, métodos de ensino, relacionação com outras disciplinas do curriculum escolar, influência na formação humana do aluno. Retirado do arquivo da Escola Secundária de Pedro Nunes (Não catalogado), 1966.

LIMA, Iolanda. O Ensino da Matemática Elementar: Finalidade, Conteúdo e Didática. Palestra, Revista de Pedagogia e Cultura, n. 3, p. 58-74, 1958.

MARTINS, Maria Fernanda. Linha de rumo do aprendizado da matemática elementar. O Modelo; os princípios da lógica matemática e da álgebra dos conjuntos. Palestra, Revista de Pedagogia e Cultura, n. 15, p. 48-71, 1962.

MATOS, José Manuel; MONTEIRO, Teresa. Construindo o conhecimento pedagógico do conteúdo em tempos da matemática moderna: as múltiplas facetas da lógica. Revista de História da Educação Matemática, v. 6, n. 2, p. 8-25, 2020.

MIRANDA, Alberto. Colóquio para Aperfeiçoamento do Ensino da Matemática no Distrito de Évora. Arquivo pessoal de Vicente Saianda, ex-estagiário do Liceu Normal de Pedro Nunes, 1966.

MONTEIRO, Teresa. Formação de Professores de Matemática no Liceu Normal de Pedro Nunes (1956-1969). (Tese de Doutoramento), Universidade Nova de Lisboa, Lisboa, 2018. 
NOGUEIRA, Maria Dulce. Algumas reflexões sobre o ensino e a aprendizagem das matemáticas elementares. Palestra, Revista de Pedagogia e Cultura, n. 12, p. 32-53, 1961.

PAIS, Maria Manuela. A estrutura actual da aritmética e da geometria no grau secundário elementar. a) A articulação com o grau primário. b) A intersecção com a matemática moderna. c) Os métodos de ensino. Palestra, Revista de Pedagogia e Cultura, n. 17, p. 107-125, 1963.

RODRIGUES, Maria Odete. A Didática Actual da Matemática no 2o Ciclo Liceal: Preocupação de Rigor Lógico; Movimento e Percepção. Retirado do arquivo da Escola Secundária de Pedro Nunes (Não catalogado), 1961.

RUA, Marília. Algumas considerações sobre o 60 ano de Matemática das turmas experimentais: conteúdos, métodos de ensino, relacionação com outras disciplinas do curriculum escolar, influência na formação humana do aluno. Retirado do arquivo da Escola Secundária de Pedro Nunes (Não catalogado), 1966.

SANTOS, Maria Alzira. 0 7ㅇ ano de matemática das turmas experimentais: alguns conteúdos e respectivas didácticas. Contribuição deste programa para uma nova estrutura da geometria liceal. Retirado do arquivo da Escola Secundária de Pedro Nunes (Não catalogado), 1967.

SANTOS, Maria Inês. 0 7ํ ano de matemática das turmas experimentais: alguns conteúdos e respectivas didácticas. Contribuição deste programa para uma nova estrutura da geometria liceal. Retirado do arquivo da Escola Secundária de Pedro Nunes (Não catalogado), 1967.

SERROTE, Plínio. Algumas considerações sobre o 6ำ ano de Matemática das turmas experimentais: conteúdos, métodos de ensino, relacionação com outras disciplinas do curriculum escolar, influência na formação humana do aluno. Palestra, Revista de Pedagogia e Cultura, n. 26, p. 108-121, 1966.

VIEIRA, Leonor. Influência da Crítica dos Fundamentos e do Material Moderno de Ensino na Estruturação e Aprendizagem da Matemática Elementar. Retirado do arquivo da Escola Secundária de Pedro Nunes (Não catalogado), 1960.

REDINHA, Joaquim. A estruturação actual da aritmética e da geometria no grau secundário elementar. Palestra, Revista de Pedagogia e Cultura, n. 17, p. 126-137, 1963.

RIBEIRO, Maria da Graça. Algumas considerações sobre o 6. 9 ano de Matemática das turmas experimentais: conteúdos, métodos de ensino, relacionação com outras disciplinas do curriculum escolar, influência na formação humana do aluno. Retirado do arquivo da Escola Secundária de Pedro Nunes (Não catalogado), 1966.

\section{Entrevistas}

Maria Alzira SANTOS, Lisboa, 1 hora e 30 minutos, 8 de junho de 2015.

Maria de Lourdes RUIZ, Vila Real de Trás-Os-Montes, 1 hora e 30 minutos, 22 de setembro de 2010.

Maria Inês SANTOS, Lisboa, 1 hora, 14 de novembro de 2014.

Joaquim Simões REDINHA, por telefone, 30 minutos, 19 de novembro de 2010. 
Joaquim Simões REDINHA, Lisboa, 3 horas, 27 de novembro de 2010.

Vicente Barão SAIANDA, Évora, 18 de março e 13 de setembro de 2010, 3 horas.

\section{Agradecimentos}

Este trabalho foi parcialmente financiado por fundos portugueses através da FCT - Fundação para a Ciência e a Tecnologia, I. P., no contexto dos projetos PTDC/CED-EDG/32422/2017 e UID/CED/02861/2019. 